\title{
Physical activity, mental health and wellbeing of Irish adolescents during Covid-19 restrictions. A re-issue of the physical activity and wellbeing study (PAWS)
}

\author{
Authors \\ John Murphy - School of Arts, Education and Movement, Dublin City University Institute of \\ Education \\ john.murphy274@mail.dcu.ie \\ *corresponding author \\ Dr Bronagh McGrane - School of Arts, Education and Movement, Dublin City University \\ Institute of Education \\ Dr Mary Rose Sweeney - School of Nursing, Psychotherapy and Community Health, Dublin \\ City University
}

\begin{abstract}
Covid-19 restrictions impacted many people's daily lives through infection, fear of infection and the implementation of restrictions on movement. Restrictions and fear of contamination impacted physical activity patterns activity and increased mental health issues globally across a variety of ages. This re-issue of a questionnaire sought to examine the impact of Covid-19 restrictions on frequency of physical activity, participation in sports, wellbeing and symptoms of anxiety and depression in Irish adolescents. 3,021 adolescents from 61 post-primary schools in the Republic of Ireland completed questionnaires. Consistent with a previous issue of the questionnaire, a minority of adolescents were found to meet the WHO's physical activity guidelines ( $11.6 \%$ of males and $5.2 \%$ of females) although there were large decreases in $1^{\text {st }}$ year males and females. Adolescents reporting elevated symptoms of depression increased from $39 \%$ to $46 \%$ with almost 3 in 5 females reporting symptoms of depression ranging from mild to extreme. Highest levels of wellbeing were found in adolescents who participated in 3 or more sports, although there was an $8 \%$ reduction in the amount of adolescents who participated in 3 or more sports. There were no changes in physical activity levels overall, despite changes within sub-groups and patterns of physical activity. There was a clear increase in symptoms of depression, with females impacted more than males. Previously active individuals were more likely to increase activity and therefore report higher levels of mental health while those who were less active were more likely to decrease activity and report lower mental health.
\end{abstract}

Keywords: Exercise; Sport; Team Sport; Resilience; Identity; Health; School

\section{Introduction}

The World Health Organisation announced a global pandemic caused by the coronavirus disease (Covid-19) on the $11^{\text {th }}$ of March 2020. Covid-19 is an infectious disease caused by a newly discovered coronavirus which is transmitted primarily through droplets of saliva or 
discharge from the nose when an infected person coughs or sneezes. Governments in various countries (including Ireland) implemented national containment strategies to limit the spread of the virus and reduce the risk of national healthcare systems becoming critically overburdened. Although physical distancing and self-isolation regulations aim to reduce person-to-person transmission of Covid-19, there are potentially significant public health implications as a result of such measures. As most attention in the early stages of Covid-19 restrictions was understandably focused on public health measures to contain the virus, the focus has since broadened to the wider and longer-term ramifications such as social isolation, delayed help-seeking for other health conditions and reduced opportunities for leisure-time physical activity (Smith et al., 2020; McGrath, Murphy \& Richardson, 2020). Reductions in leisure-time physical activity may lead to less social interaction, increased risk of cardiometabolic diseases and has been linked with increased risks from Covid-19 itself. For example, a reduction in physical activity and an increase in sedentary behaviours may adversely affect immune function and enhance the risk for chronic health conditions (Sallis, Adlakha, Oyeyimi \& Salvo, 2020).

Physical activity is defined as any bodily movement that requires energy expenditure and is produced by skeletal muscle while exercise is a planned, structured and repetitive subcategory of physical activity that aims to increase one or more components of physical fitness (Bull et al., 2020). Regular exposure to physical activity has displayed beneficial effects on the immune system and counteracts many comorbidities such as type ii diabetes, hypertension and obesity (Woods et al., 2020) with growing evidence for the support of positive mental health (Biddle, Ciaccioni, Thomas \& Vergeer, 2019). Mental health disorders are the second leading cause of global burden of disease and growing rapidly (Kassebaum et al., 2017) with depression alone accounting for more than 44 million years lived with disability (Schuch et al., 2018). Mental health issues in adolescents are increasing both globally (Kieling et al., 2011), in Europe (McMahon et al., 2017) and in Ireland (Dooley, O'Connor, Fitzgerald \& O'Reilly, 2019) with 4 in 10 adolescents recently reporting elevated symptoms of depression or anxiety (Murphy, Sweeney \& McGrane, 2020). Physical activity is well recognised as a key risk factor for the management and prevention of mental ill-health, including anxiety and depression (Teychenne et al., 2020). Higher frequencies of physical activity have been linked with reduced symptoms of anxiety and depression, and higher levels of wellbeing in adolescents (Murphy et al., 2020, McMahon et al., 2017). Experimental research has also shown how exposure to aerobic exercise (Lin et al., 2020), resistance exercise (Gordon, McDowell, Lyons \& Herring, 2020), and a combination of both types of exercise can improve mental health and wellbeing in adolescents (Goldfield et al., 2019). Along with type of activity, the context has also been highlighted as important for mental health (Teychenne et al., 2020). Various aspects contribute to the context within which physical activity is carried out such as social interaction, peer groups, mastery of goals/skills, enjoyment, choice and a sense of belonging (Biddle, Mutrie, Gorely \& Faulkner, 2021). Many of these were impacted by Covid-19 restrictions due to a lack of travel outside $5 \mathrm{~km}$ from the home and social distancing guidelines especially social interaction and time spent among peer groups.

Cross-sectional research has highlighted changes in patterns of physical activity during Covid19 restrictions in Ireland (McGrath, Murphy \& Richardson, 2020; O'Kane et al., 2021) and internationally (Faulkner et al., 2021). Initial introductions of containment strategies, such as lockdowns, may have created barriers to physical activity for some, although changes in social 
and work patterns allowed others to find additional opportunities to be physically active (Faulkner et al., 2021). Reduced commute times and access to various online platforms have increased opportunities to partake in previously less popular activities such as HIIT, pilates, yoga and aerobics classes. 'Daily exercise' was highlighted by many governments as a justifiable reason for leaving your house during containment strategies. Changes in physical activity patterns have been inconsistent across populations with some increases (Quispe, Panca, Ramos \& Cornejo, 2021), some decreases (Brown et al., 2021) and some reporting no change in overall frequency (O'Kane et al., 2021) although there were a number of changes in the types of activity that were partaken in and when activity was undertaken (Faulkner et al., 2021). It is interesting to note however, investigations that looked at psychological outcomes as well as physical activity found maintaining or increasing physical activity during covid-19 restrictions was associated with higher wellbeing and lower symptoms of depression and anxiety while negative changes in physical activity were associated with lower wellbeing and higher symptoms of depression and anxiety across populations (Faulkner et al., 2021; O’Kane et al., 2021; McGrath et al., 2021).

The future of Covid-19 is unknown with restrictions and social distancing possibly in place for some time to come (Kissler, Tedijanto, Goldstein, Grad \& Lipsitch, 2020). Prior to the pandemic, the mental health and wellbeing of adolescents in Ireland was of concern (Murphy et al., 2020; Dooley et al. , 2019) and so it is of importance that we understand how the restrictions implemented to control the transmission of Covid-19 affect their health and wellbeing. The findings of this study may inform future interventions and public health strategies aimed at supporting those seeking to be active during unprecedented times such as societal lockdowns, school closures or enforced layoffs from physical activity like injuries. The aim of this study was to explore the impact of Covid-19 restrictions on physical activity levels in adolescents and the impact on mental health outcomes by comparing data captured pre- (October 2019) and post-lockdown (November 2020), in the Republic of Ireland.

\section{Methods}

This was a re-issue of a previous national questionnaire (Murphy et al., 2020). A crosssectional study design was employed across post-primary schools in the Republic Of Ireland. Invitations were emailed to all 144 schools who participated in the original questionnaire. Data collection took place in November 2020.

\section{Data Collection}

Written consent was obtained from the Principal of each school prior to the questionnaire being distributed. Parental consent forms and plain language statements were issued to all participants prior to data being collected. Participants were informed of the anonymity of all responses. All questionnaires were administered through an online Google form and could be completed via desktop computer, laptop, tablet or mobile phone. The means of administering the questionnaire was at the discretion of each participating school.

\section{Physical Activity}

Habitual physical activity was assessed via a modified version of the Take PART questionnaire by measuring the number of days during the past 14 that participants had accumulated 60 minutes of moderate to vigorous physical activity (MVPA). The survey item assessing physical 
activity read: "During a typical 2-week period, on how many days were you physically active for a total of at least 60 minutes? For each day, add up all the time you spent in physical activity. Count up the days with at least 60 minutes of physical activity in a typical 2-week period." A graphic summarising moderate-to-vigorous physical activity, with examples, was also included in the questionnaire. Responses ranged from 0 to 14 days. Participants were also asked to rate if they were "more active", "less active", or "about the same" due to the Covid-19 restrictions.

\section{Participation in sport}

A further survey item asked about regular engagement in one or more sports since the onset of Covid-19 restrictions, with possible "Yes" or "No" responses (McMahon et al., 2017; Murphy et al., 2020). Participants were provided with a text box to list the sports, up to three, that they currently participated in. The lead researcher counted all sports listed and participants were coded as either " 0 ", "1", " 2 " or " $3+$ " sports. The lead researcher also coded activities as team sport or individual/fitness activity. Team sport was defined as "those that typically involved three or more players on each side who compete concurrently" (Zhou, Heim \& O'Brien, 2015). Participants were assigned to the "team sport" category if they listed at least one activity that met the definition. Participants were assigned to "individual sport/fitness activity" category if they listed individual sport or fitness activities but no team sport.

\section{Mental health}

Symptoms of depression were assessed using the Beck Depression Inventory (BDI) (Beck, Steer \& Carbin, 1988). Specific symptoms of depression experienced by participants over the previous two weeks are assessed by the BDI. As one question relation to loss of libido was deemed unsuitable for adolescent participants, it was excluded from the questionnaire (Kendall, Hollon, Beck, Hammem \& Ingram, 1987). Responses for each individual symptom range from 0 to 3 , with 3 indicating a higher severity of that particular symptom. Scores are added together with a minimum possible score of 0 indicating no symptoms of depression and a maximum possible score of 60 indicating extreme symptoms of depression. Adolescent samples have previously demonstrated very good reliability and validity when assessed using the BDI (Teri, 1982; Steer, Kumar, Ranieri \& Beck, 1998).

Symptoms of anxiety were assessed using the Beck Anxiety Inventory (BAI) (Steer \& Beck, 1997). The BAI is comprised of 21 self-report questions. Responses for each individual symptom range from 0 to 3 , with a higher number including a higher severity of a symptom. Scores are added together with a minimum possible score of 0 indicating no symptoms and a maximum possible score of 63 indicating extreme symptoms of anxiety. Adolescent samples have previously demonstrated very good reliability and validity when assessed using the Beck Anxiety Inventory (Fydrich, Dowdall \& Chambless, 1992; Steer, Kumar, Ranieri \& Beck, 1995). The Warwick Edinburgh Mental Wellbeing Scale (WEMWS) (Stewart-Brown \& Janmohamed, 2008) was used to measure positive psychological wellbeing. 14 questions are asked with responses ranging from 1 to 5 leading to a minimum score of 14 and a maximum possible score of 70. The WEMWS has been previously validated in a sample of adolescents (Clarke et al., 2011). 


\section{Statistical analyses}

Participants were divided into categories of physical activity based on the frequency reported. Most Active (60 minutes or more of activity on 8-14 days a typical 2-week period), Somewhat Active (60 minutes of more of activity on 4-7 days in a typical 2-week period), or Least Active 60 minutes or more of activity on 0-3 days in a typical 2-week period). Participants who reported meeting the daily physical activity guidelines of 60 minutes of moderate-to-vigorous physical activity per day on all 14 days in a typical 2-week period were added to a sub-group known as Sufficiently Active (according to WHO guidelines. Mean frequency of physical activity between males and females was compared using t-tests.

Two-way ANOVAs were used to compare mean scores between all sub-groups on psychological variables (WEMWS, BDI, BAI) and between males, females and those who identified as neither male or female. Post-hoc between-group comparisons were conducted using Tukey's HSD with Bonferroni correction.

Gender was controlled for when conducting analyses between physical activity sub-groups due to the significant differences in prevalence of mental health problems and frequency of physical activity between males and females. The open-source statistical software package $R$ ( $R$ Core Team, 2014) was used to conduct all analyses. The ggplot2 package (Wickham, 2009) was used to produce all figures.

\section{Research Ethics}

Approved by DCU Ethics Committee (DCUREC/2019/107).

\section{Results}

Table 1: Participants by year and gender

\begin{tabular}{|lcccc|}
\hline Year & Male & Female & Other & Total \\
\hline $\mathbf{1}^{\text {st }}$ Year & 335 & 401 & 10 & 746 \\
\hline $\mathbf{2}^{\text {nd }}$ Year & 278 & 397 & 6 & 681 \\
\hline $\mathbf{3}^{\text {rd }}$ Year & 139 & 224 & 3 & 366 \\
\hline $\mathbf{4}^{\text {th }}$ Year & 219 & 262 & 3 & 484 \\
$\mathbf{5}^{\text {th }}$ Year & 265 & 238 & 8 & 511 \\
\hline $\mathbf{6}^{\text {th }}$ Year & 90 & 138 & 5 & 233 \\
\hline Total & 1326 & 1660 & 35 & 3021 \\
\hline
\end{tabular}

\section{Participant characteristics}

64 schools initially registered interest in the study of which 33 fully took part. Schools that were unable to fully participate listed involvement in other research, lack of time and no Principal consent as the main reasons. 3021 participants were recruited from 33 schools representing 16 different counties in Ireland giving a very good geographical spread. Of the 3021,1660 (54.9\%) identified as female, 1326 (43.8\%) identified as male while a further 35 $(0.2 \%)$ identified as neither male nor female (referred to as "other" for the purposes of reporting throughout). $1^{\text {st }}$ year had the most participant $(n=746,24.6 \%)$, followed by $2^{\text {nd }}$ year $(n=681,22.5 \%), 5^{\text {th }}$ year $(n=511,16.9 \%)$, transition year $(n=484,16.1 \%), 3^{\text {rd }}$ year $(n=366$, $12.1 \%$ ) and least participants from $6^{\text {th }}$ year $(n=233,7.7 \%)$. Ages ranged from 12 to 19 years. The mean age of participants was 14.5 ( $\mathrm{sd}=1.6)$. 


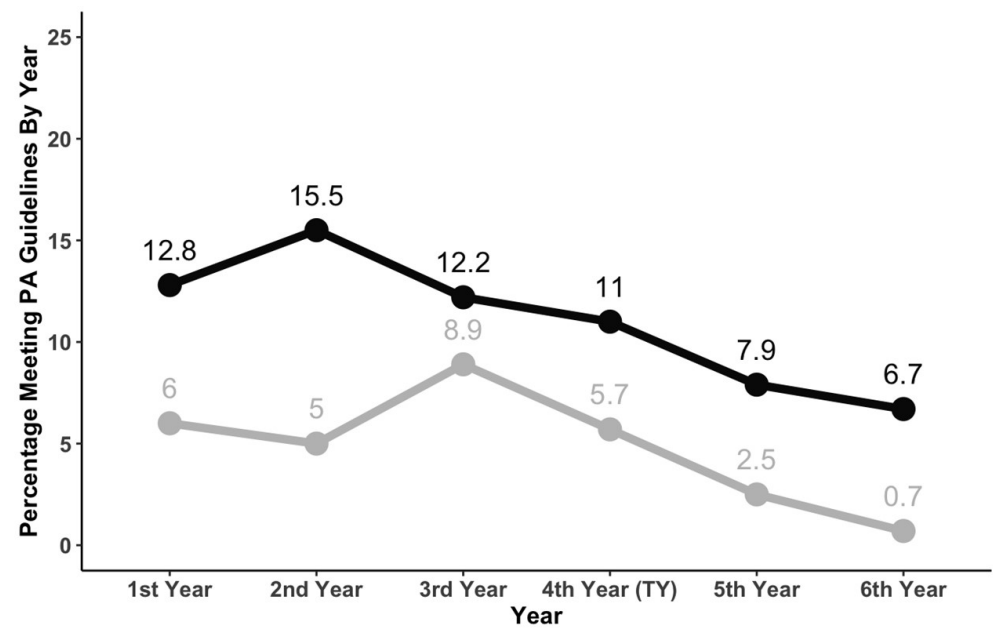

Figure 1: Percentage of students meeting PA guidelines by year and gender

\section{Frequency of physical activity and sports participation}

Overall, this study found that $8 \%$ of Irish adolescents met the WHO's guidelines of 60 minutes moderate-to-vigorous physical activity every day during Covid-19 restrictions. $11.6 \%$ of males and $5.2 \%$ of females reported meeting physical activity guidelines. The percentage of adolescents meeting physical activity guidelines increased from $9 \%$ in $1^{\text {st }}$ year to $10 \%$ in $2^{\text {nd }}$ and $3^{\text {rd }}$ year before following a linear trend of reduction in both males and females to $3 \%$ in $6^{\text {th }}$ year (figure 1 ).

Significantly more females $(17.7 \%)$ than males (13.1\%) were found in the least active subgroup and in the somewhat active sub-group (40.9\% of females, $32.3 \%$ of males) while significantly more males $(54.6 \%)$ than females $(41.4 \%)$ were found in the most active subgroup.

Table 2: Frequency of physical activity among males and females by year

\begin{tabular}{|c|c|c|c|c|c|c|c|c|}
\hline & \multicolumn{2}{|c|}{$\begin{array}{l}\text { Least Active } \\
\text { (0-3 days) } \\
\text { (\% within sex) }\end{array}$} & \multicolumn{2}{|c|}{$\begin{array}{l}\text { Somewhat Active } \\
\text { ( } 4-7 \text { days) } \\
\text { (\% within sex) }\end{array}$} & \multicolumn{2}{|c|}{$\begin{array}{l}\text { Most Active } \\
\text { (8-14 days) } \\
\text { (\% within sex) }\end{array}$} & \multicolumn{2}{|c|}{$\begin{array}{l}\text { Sufficiently Active } \\
\text { (\% within sex) }\end{array}$} \\
\hline & Male & Female & Male & Female & Male & Female & Male & Female \\
\hline $1^{\text {st }}$ Year & $14.4 \%$ & $15.4 \%$ & $31.4 \%$ & $36.9 \%$ & $54.2 \%$ & $47.7 \%$ & $12.8 \%$ & $6.0 \%$ \\
\hline $2^{\text {nd }}$ Year & $14.2 \%$ & $12.4 \%$ & $29.1 \%$ & $43.7 \%$ & $56.7 \%$ & $43.9 \%$ & $15.5 \%$ & $5.0 \%$ \\
\hline $3^{\text {rd }}$ Year & $8.2 \%$ & $21.8 \%$ & $32.1 \%$ & $35.9 \%$ & $59.7 \%$ & $42.3 \%$ & $12.2 \%$ & $8.9 \%$ \\
\hline $4^{\text {th }}$ Year & $9.3 \%$ & $12.7 \%$ & $36.1 \%$ & $38.6 \%$ & $54.6 \%$ & $48.6 \%$ & $11.0 \%$ & $5.7 \%$ \\
\hline $5^{\text {th }}$ Year & $15.1 \%$ & $22.8 \%$ & $36.1 \%$ & $48.7 \%$ & $48.8 \%$ & $28.6 \%$ & $7.9 \%$ & $2.5 \%$ \\
\hline $6^{\text {th }}$ Year & $15.9 \%$ & $34.4 \%$ & $26.1 \%$ & $44.5 \%$ & $58.0 \%$ & $21.1 \%$ & $6.7 \%$ & $0.7 \%$ \\
\hline Mean & $13.1 \%$ & $17.7 \%$ & $32.3 \%$ & $40.9 \%$ & $54.6 \%$ & $41.4 \%$ & $11.6 \%$ & $5.2 \%$ \\
\hline
\end{tabular}

$80 \%$ of the entire sample of adolescents reported engaging in at least one sport during Covid-19 restrictions while $68 \%$ reported engaging in at least one team sport although there were large differences in terms of sex ( $58 \%$ of females, $76 \%$ of males). 
$36.3 \%$ of adolescents sampled (33.4\% males, $38.6 \%$ females) reported being more active during Covid19 restrictions, $41.6 \%$ (43.8\% males, 39.7\% females) reported being less active, $18.7 \%$ (19.9\% males, $17.7 \%$ females $)$ reported having about the same levels of physical activity while $3.4 \%(2.7 \%$ males, $3.9 \%$ females) were unsure.

\section{Mental health outcomes}

\section{Symptoms of depression: BDI}

$46 \%$ of the entire sample reported mild to extreme symptoms of depression with $8 \%$ reporting symptoms as either severe or extreme. 31\% of males reported symptoms of depression with $3 \%$ in either the severe or extreme categories. $11 \%$ of females reported symptoms of depression with $11 \%$ in either the severe or extreme categories. $89 \%$ of those who identified as neither male nor female reported symptoms of depression with $32 \%$ in the severe or extreme categories. The lowest symptoms of depression were found in $1^{\text {st }}$ year and transition year males, and $1^{\text {st }}$ year females. The highest symptoms of depression were found in $2^{\text {nd }}$ year and $6^{\text {th }}$ year males, and $3^{\text {rd }}$ and $6^{\text {th }}$ year females. Significant differences were found between $1^{\text {st }}$ years and $2^{\text {nd }}$ years $(p=0.008), 1^{\text {st }}$ years and $3^{\text {rd }}$ years $(p=0.001), 1^{\text {st }}$ years and $6^{\text {th }}$ years $(p=0.002), 4^{\text {th }}$ years and $6^{\text {th }}$ years $(p=0.01)$, and between $5^{\text {th }}$ years and $6^{\text {th }}$ years $(p$ $=0.004)$. Significant differences in mean depression scores were found between males and females $(p=0.001)$, males and other $(p=0.001)$, and between females and other $(p=0.002)$.

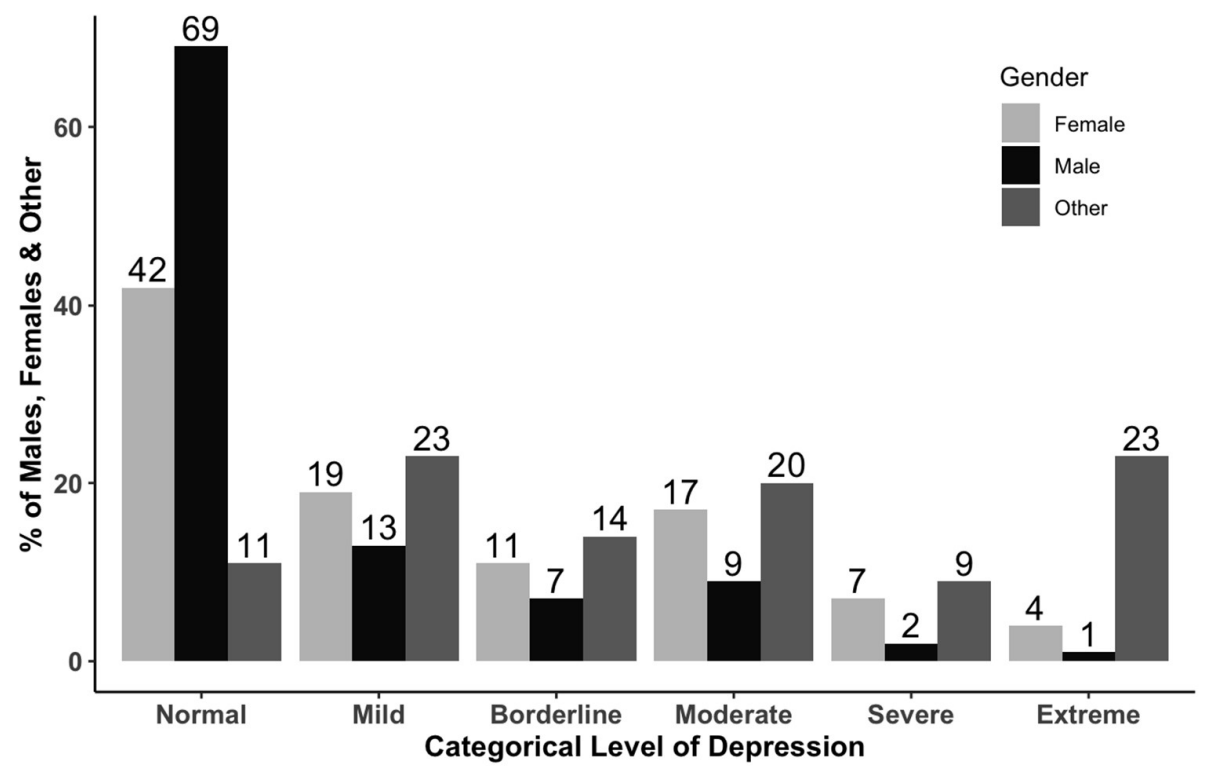

Figure 2: Participants by category of depression and gender

\section{Symptoms of anxiety: BAI}

$31 \%$ of the entire sample reported symptoms of anxiety that were either moderate or concerning. $17 \%$ of males, $40 \%$ of females and $71 \%$ of those who identified as neither male nor female reported symptoms that range from moderate to concerning. Lowest symptoms of anxiety were found transition year and $5^{\text {th }}$ year males, and $1^{\text {st }}$ year females. Highest symptoms of anxiety were found in $6^{\text {th }}$ year males, and $5^{\text {th }}$ year and $6^{\text {th }}$ year females. Significant differences were found in mean anxiety scores between $1^{\text {st }}$ years and $2^{\text {nd }}$ years ( $p$ $=0.001), 1^{\text {st }}$ years and $3^{\text {rd }}$ years $(p=0.01), 1^{\text {st }}$ years and $6^{\text {th }}$ years $(p=0.002)$, and between $4^{\text {th }}$ years and $6^{\text {th }}$ years $(p=0.03)$. Significant differences in mean anxiety scores were found 
between males and females $(p=0.001)$, males and other $(p=0.001)$, and between females and other $(p=0.002)$.

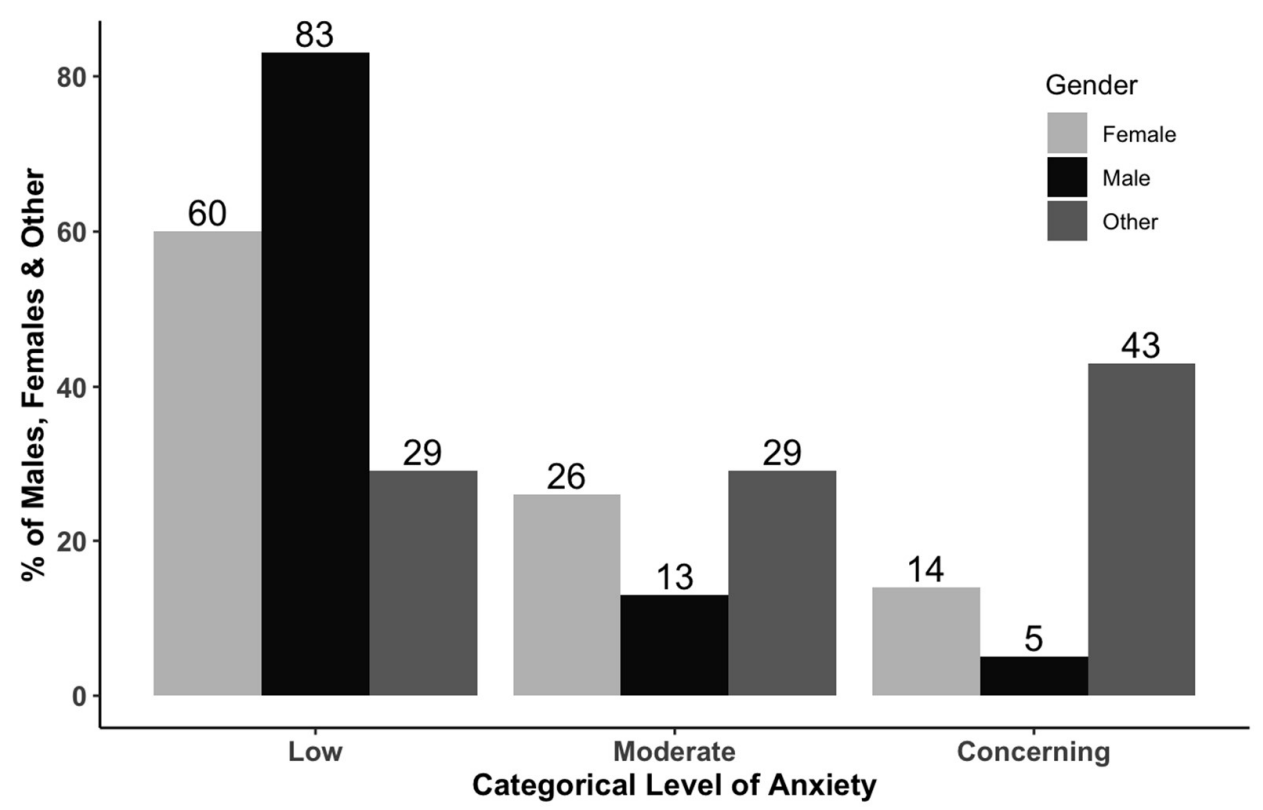

Figure 3: Participants by category of anxiety and gender

\section{Wellbeing: WEMWS}

The mean score on the Warwick Edinburgh Mental Wellbeing Scale was $46.7 \pm 9.4$ out of a maximum possible 70. Significant differences were found between $1^{\text {st }}$ years and $2^{\text {nd }}$ years $(p$ $=0.003), 1^{\text {st }}$ years and $3^{\text {rd }}$ years $(p=0.001), 1^{\text {st }}$ years and $5^{\text {th }}$ years $(p=0.004), 1^{\text {st }}$ years and $6^{\text {th }}$ years $(p=0.001), 2^{\text {nd }}$ years and $4^{\text {th }}$ years $(p=0.02), 2^{\text {nd }}$ years and $6^{\text {th }}$ years $(p=0.002), 3^{\text {rd }}$ years and $6^{\text {th }}$ years $(p=0.003), 4^{\text {th }}$ years and $6^{\text {th }}$ years $(p=0.001)$, and between $5^{\text {th }}$ years and $6^{\text {th }}$ years $(p=0.001)$. Highest wellbeing scores were found in $1^{\text {st }}$ years and $4^{\text {th }}$ years with the lowest wellbeing scores found in $6^{\text {th }}$ years. Significant differences in mean wellbeing cores were also found between males and females $(p=0.005)$, males and other $(p=0.001)$, and between female and other $(p=0.008)$.

Table 3: Mental health outcomes by year and gender

\begin{tabular}{|l|lll|lll|lll|}
\hline Year & \multicolumn{3}{|c|}{$\begin{array}{c}\text { Depression } \\
\text { Mean (SD) }\end{array}$} & \multicolumn{3}{c|}{$\begin{array}{c}\text { Anxiety } \\
\text { Mean (SD) }\end{array}$} & \multicolumn{3}{c|}{ Wellbeing } \\
& \multicolumn{3}{|c|}{ Mean (SD) } \\
\hline & Male & Female & Other & Male & Female & Other & Male & Female & Other \\
$\mathbf{1}^{\text {st }}$ & $7.4(3.9)$ & $12.2(5.4)$ & $35.4(9.6)$ & $11.1(4.7)$ & $16.2(5.9)$ & $40.6(6.5)$ & $50.7(8.3)$ & $47.6(9.1)$ & $28.7(7.1)$ \\
$\mathbf{2}^{\text {nd }}$ & $9.6(5.5)$ & $15.2(6.0)$ & $25.5(7.8)$ & $12.6(6.8)$ & $20.3(6.7)$ & $26.5(7.3)$ & $48.2(9.9)$ & $44.5(9.2)$ & $36.5(9.3)$ \\
$\mathbf{3}^{\text {rd }}$ & $8.6(4.8)$ & $17.0(6.1)$ & $25.3(6.7)$ & $11.6(4.9)$ & $20.0(6.6)$ & $36.7(3.8)$ & $49.0(9.1)$ & $44.0(9.9)$ & $39.0(6.2)$ \\
$\mathbf{4}^{\text {th }}$ & $7.9(3.8)$ & $15.2(5.7)$ & $13.7(1.2)$ & $10.5(5.1)$ & $20.3(6.2)$ & $9.7(3.2)$ & $50.0(8.3)$ & $45.6(8.7)$ & $58.0(13.9)$ \\
$\mathbf{5}^{\text {th }}$ & $8.7(4.3)$ & $15.6(5.8)$ & $20.4(5.3)$ & $10.4(5.4)$ & $21.7(7.0)$ & $32.4(6.5)$ & $48.5(9.0)$ & $44.4(8.4)$ & $41.2(9.6)$ \\
$\mathbf{6}^{\text {th }}$ & $9.7(5.0)$ & $17.8(5.9)$ & $22.4(5.4)$ & $14.4(6.3)$ & $21.6(6.9)$ & $24.2(6.9)$ & $46.2(8.3)$ & $40.3(8.8)$ & $38.2(8.4)$ \\
\hline $\mathbf{M}^{\text {Mean }}$ & $8.5(4.5)$ & $15.0(5.8)$ & $25.7(7.6)$ & $11.4(5.5)$ & $19.6(6.6)$ & $31.0(7.4)$ & $49.1(8.9)$ & $45.0(9.3)$ & $37.7(11.4)$ \\
\hline
\end{tabular}




\section{Frequency of physical activity, sport participation and mental health outcomes}

Significant differences were found between physical activity sub-groups on all of the mental health outcomes examined ( $p<0.005$ for both males and females on BDI, BAI and WEMWS after Bonferroni correction). Higher frequencies of physical activity were associated with higher scores on the WEMWS and lower self-reported symptoms of depression and anxiety were associated.

\section{Frequency of physical activity sub-group}

Significant differences between the Least Active and Somewhat Active groups were found on all scores examined in post hoc sub-group comparisons. The Somewhat Active group had higher wellbeing scores $(p=0.001)$ and lower symptoms of depression $(p=0.001)$ and anxiety $(p=0.007)$ than the Least Active group. The Most Active group also displayed significantly higher wellbeing scores $(p=0.003)$ and lower symptoms of depression $(p=0.001)$ and anxiety $(p=0.002)$ than the Somewhat Active group in post hoc sub-group comparisons.

\section{Participation in sport}

Participation in sport was found to have significantly higher wellbeing scores and significantly lower symptoms of depression and anxiety in the entire cohort of participants. Highest wellbeing scores were found in participants who participate in 3 or more sport sports. Lowest symptoms of depression were found in both males and females who participated in 3 or more sports while the lowest symptoms of anxiety were found in males who play 3 or more sports but in females who play 2 sports. Significant differences in wellbeing scores were found between those who play no sports and 1 sport $(p=0.001)$, no sport and 2 sports $(p=0.001)$, no sport and 3 or more sports $(p=0.001), 1$ sport and 2 sports $(p=0.002), 2$ sports and 3 or more sports $(p=0.005)$, and 2 sports and 3 sports $(p=0.002)$. Significant differences in symptoms of depression were found between those who play no sport and 1 sport $(p=0.001)$, no sport and 2 sports $(p=0.001)$, no sport and 3 or more sports $(p=0.001), 1$ sport and 3 or more sports $(p=0.002)$, and between 2 sports and 3 sports $(p=0.009)$. Significant differences in symptoms of anxiety were found between those who play no sport and 1 sport $(p=0.001)$, no sport and 2 sports $(p=0.001)$, no sport and 3 or more sports $(p=0.001)$, and between 1 sport and 3 or more sports $(p=0.002)$.

Perceived changes in physical activity

Wellbeing was highest in males and females who reported being more active or being about the same levels of physical activity during Covid-19 restrictions. Significant differences in wellbeing scores were found between those who were less active and more active $(p=0.001)$, less active and about the same $(p=0.001)$, less active and unsure $(p=0.01)$, unsure and more active $(p=0.003)$, and between unsure and about the same $(p=0.001)$. Lowest symptoms of depression were found in males and females who were about the same levels of physical activity while the highest symptoms were found in males and females who were unsure. Significant differences in symptoms of depression were found between those who were less active and about the same $(p=0.001)$, unsure and more active $(p=0.03)$, unsure and about the same $(p=0.001)$, and between more active and about the same $(p=0.003)$. Lowest symptoms of anxiety were found in males who were more active and females who were about the same while the highest symptoms of anxiety were found in males who were less active and females who were unsure. Significant differences in symptoms of anxiety were found between those who were less active and about the same $(p=0.01)$, and between those who were unsure and about the same $(p=0.01)$. 


\section{Associations between mental health outcomes}

A significant moderate inverse association $(p=0.001, r=-0.54)$ was found between wellbeing and symptoms of anxiety. A significant strong inverse association $(p=0.002, r=-0.69)$ was found between wellbeing and symptoms of depression. A significant strong positive association as found between symptoms of depression and symptoms of anxiety $(p=0.005$, $r=0.7)$.

Table 4: Physical activity sub-groups and associations with wellbeing, depression and anxiety by gender

\begin{tabular}{|c|c|c|c|c|c|c|c|c|}
\hline \multirow{2}{*}{$\begin{array}{l} \\
\text { Physical Activity } \\
\text { Subgroup }\end{array}$} & \multicolumn{2}{|c|}{ Percentage of } & \multicolumn{2}{|c|}{$\begin{array}{l}\text { Wellbeing } \\
\text { Mean (SD) }\end{array}$} & \multicolumn{2}{|c|}{$\begin{array}{c}\text { Depression } \\
\text { Mean (SD) }\end{array}$} & \multicolumn{2}{|c|}{$\begin{array}{c}\text { Anxiety } \\
\text { Mean (SD) }\end{array}$} \\
\hline & Male & Female & Male & Female & Male & Female & Male & Female \\
\hline $\begin{array}{l}\text { Least Active } \\
\text { (0-3 days) }\end{array}$ & $13.1 \%$ & $17.7 \%$ & $45.7(9.4)$ & $41.9(9.8)$ & $12.3(10.6)$ & $17.8(12.7)$ & $15.4(11.1)$ & $21.4(14.2)$ \\
\hline $\begin{array}{l}\text { Somewhat Active } \\
\text { (4-7 days) }\end{array}$ & $32.3 \%$ & $40.9 \%$ & $48.8(8.5)$ & $45.2(8.9)$ & $8.8(9.1)$ & $14.4(11.2)$ & $11.8(11.0)$ & $19.3(13.1)$ \\
\hline $\begin{array}{l}\text { Most Active } \\
\text { (8-14 days) }\end{array}$ & $54.6 \%$ & $41.4 \%$ & $50.5(8.1)$ & $47.6(9.2)$ & $7.1(9.7)$ & $14.0(10.3)$ & $10.3(10.1)$ & $18.8(12.5)$ \\
\hline $\begin{array}{l}\text { Number of Sports } \\
\text { Played }\end{array}$ & Male & Female & Male & Female & Male & Female & Male & Female \\
\hline 0 & $15 \%$ & $25 \%$ & $44.4(9.6)$ & $42.7(9.8)$ & $12.4(11.1)$ & $17.5(12.6)$ & $13.6(12.6)$ & $22.0(14.0)$ \\
\hline 1 & $29 \%$ & $36 \%$ & $48.7(8.9)$ & $44.8(9.0)$ & 7.9(10.3) & $15.1(11.3)$ & $11.5(10.5)$ & $20.1(13.5)$ \\
\hline 2 & $33 \%$ & $30 \%$ & $50.0(7.5)$ & $46.3(8.8)$ & $8.7(8.5)$ & $13.5(10.2)$ & $11.6(10.9)$ & $17.5(12.4)$ \\
\hline $3+$ & $23 \%$ & $10 \%$ & $51.5(8.6)$ & $47.0(8.5)$ & $6.5(8.8)$ & $13.1(10.3)$ & $9.7(10.3)$ & $18.1(12.1)$ \\
\hline Team Sport & Male & Female & Male & Female & Male & Female & Male & Female \\
\hline Yes & $76 \%$ & $60 \%$ & $50.2(8.1)$ & $45.9(8.5)$ & $7.6(8.5)$ & $14.1(10.5)$ & $10.8(10.2)$ & $18.3(12.4)$ \\
\hline No & $24 \%$ & $40 \%$ & $45.6(9.5)$ & $43.6(9.7)$ & $11.4(11.3)$ & $16.4(12.4)$ & $13.4(12.4)$ & $21.6(13.8)$ \\
\hline $\begin{array}{l}\text { Changes In PA } \\
\text { Levels }\end{array}$ & Male & Female & Male & Female & Male & Female & Male & Female \\
\hline Unsure & $2.7 \%$ & $3.9 \%$ & $44.2(13.6)$ & $42.0(9.0)$ & $11.2(5.4)$ & $16.8(5.8)$ & $11.7(5.8)$ & $22.2(6.1)$ \\
\hline Less Active & $43.8 \%$ & $39.7 \%$ & $48.1(8.9)$ & $43.4(9.2)$ & $9.1(4.5)$ & $16.6(5.9)$ & $12.2(5.5)$ & $20.2(6.6)$ \\
\hline More Active & $33.4 \%$ & $38.6 \%$ & $50.5(8.1)$ & $46.1(9.2)$ & $8.0(4.6)$ & $14.4(5.8)$ & $10.4(5.3)$ & $19.7(6.4)$ \\
\hline About The Same & $19.9 \%$ & $17.7 \%$ & $50.0(8.9)$ & $46.9(8.8)$ & $7.5(4.3)$ & $12.1(5.3)$ & $11.3(6.0)$ & $17.4(6.8)$ \\
\hline
\end{tabular}

\section{Discussion}

Similar to previous investigations of physical activity in Irish adolescents (Murphy et al., 2020; Woods et al., 2019), only a small minority (8\%) met physical activity recommendations $(11.6 \%$ of males, $5.2 \%$ of females). Meeting physical activity guidelines on a greater number of days was associated with higher levels of wellbeing and lower symptoms of anxiety and depression in both males and females. As has been previously shown in adult populations (Faulkner et al., 2021), this study demonstrated that individuals with negative perceived changes in physical activity during Covid-19 restrictions reported lower wellbeing and higher symptoms of depression and anxiety with those unsure of activity levels reporting the most negative outcomes of all sub groups. $44 \%$ of males reported being less active during restrictions compared to $40 \%$ of females. This may be due to greater male than female involvement $(76 \%$ 
$v 58 \%$ ) in organised team sport which was more severely impacted by restrictions than many other individual sport or fitness activities. Approximately one third of males (33.4\%) reported being more active during restrictions compared to a higher percentage of females (38.6\%). Less than one fifth of adolescents overall reported the same levels of physical activity with more males (19.9\%) remaining the same than females (17.7\%).

Throughout the entire sample there was a 7\% increase of Irish adolescents reporting symptoms of depression that are outside the normal range as it increased from $39 \%$ to $46 \%$. Within this there was no change in those who identified as neither male nor female (89\%) while there was an increase from $28 \%$ to $31 \%$ in males and a large increase from $47 \%$ to $58 \%$ in females with a worrying $11 \%$ reporting either severe or extreme symptoms. Highest symptoms of depression were once again reported by females in $3^{\text {rd }}$ and $6^{\text {th }}$ year suggesting state examinations, and the uncertainty surrounding them, may play a role. The highest symptoms of depression reported by males were in $6^{\text {th }}$ year also and $2^{\text {nd }}$ year which may be caused by the interruption to their $1^{\text {st }}$ year in post primary school and the lack of extracurricular and sporting activities on offer. Lowest symptoms of depression were reported by both $1^{\text {st }}$ year males and females. Increased symptoms of depression are consistent with longitudinal findings from the wider population during Covid-19 restrictions (Hyland et al., 2021). Adolescents and younger adults were identified as the most likely to report higher symptoms of depression during restrictions (Hyland et al., 2021; Brown et al., 2021) as higher levels of loneliness (McHugh et al., 2020) and lower levels of resilience (Shapero et al., 2019) identified as key risk factors (Hyland et al., 2021). Notably, individuals living in urban settings were less likely to develop increased symptoms of depression in a longitudinal study (Hyland et al., 2021) which suggests increased opportunities for social interaction may protect against symptoms of depression and could be one of the main factors also present through engagement in team sport.

Changes in symptoms of anxiety were less prevalent with only a $1 \%$ increase in those reporting symptoms outside the normal range ( $2 \%$ increase in males, $1 \%$ increase in females). This is consistent with a longitudinal assessment of mental health outcomes in the Republic of Ireland where slight increases in symptoms of anxiety were detected at the outset of the pandemic but these had returned to pre-lockdown levels after 6 weeks (Hyland et al., 2021). A closer look at symptoms of anxiety by year group revealed a reduction in symptoms among all male groups bar $6^{\text {th }}$ years who increased as did $1^{\text {st }}$ and $5^{\text {th }}$ year females. Well established risk factors for elevated symptoms of anxiety include being female (Hyland et al., 2016), as is consistent with current findings along with lower levels of Conscientiousness and higher levels of Openness (Costache et al., 2020) and higher levels of loneliness (Beckhuis et al., 2016) suggest that less opportunities for participation in extra-curricular sporting activities, are likely to play a part. Extra-curricular activities, such as engagement in sport, provide adolescents with an opportunity for increased physical activity and social interactions (Panza et al., 2020), both of which have been independently established as protective factors against symptoms anxiety and depression (Eime et al., 2013; Fraser-Thomas, Cote \& Deakin, 2005; Paluska \& Schwenk, 2000).

There was no meaningful change in terms of wellbeing across the entire sample although there were reductions in mean wellbeing score among both males and females in $2^{\text {nd }}$ year and $6^{\text {th }}$ year. Once again, this is difficult to explain although the largest reduction in adolescents meeting physical activity guidelines was in $2^{\text {nd }}$ years $(-3 \%)$ when compared to the previous edition of this questionnaire (Murphy et al., 2020) while the largest increase in 
adolescents in the Least Active sub-group compared to the previous edition was in $6^{\text {th }}$ years $(+4 \%)$. An increase in participants in the Least Active group suggests greater sedentary time which has been repeatedly associated with deteriorated wellbeing in large-scale epidemiological studies across both adolescent (Burkhardt \& Brennan, 2012; Biddle et al., 2019) and adult populations (Zhai, Zhang \& Zhang, 2015).

The overall number of adolescents meeting physical activity guidelines remained the same as the previous edition (Murphy et al., 2020) although there were a number of differences between sub-groups. The previous edition found $1^{\text {st }}$ year males and females had the highest frequency of physical activity with clear declines throughout school thereafter. The current findings show that $7 \%$ less males and $3 \%$ less females met the physical activity guidelines during Covid-19 restrictions with other reductions in $3^{\text {rd }}$ year males $(-2.5 \%)$ and $2^{\text {nd }}$ year females (-4.2\%). The largest increases were found in $3^{\text {rd }}$ year females $(+4 \%)$ and $4^{\text {th }}$ year males $(+3 \%)$. Less than $1 \%$ of females in $6^{\text {th }}$ year met the physical activity guidelines.

The key sub-group differences were observed in the Least Active and Most Active groups. $1^{\text {st }}$, $2^{\text {nd }}$ and $6^{\text {th }}$ year males increased by $6 \%, 3 \%$ and $3 \%$ respectively in the Least Active group while only $6^{\text {th }}$ year females had increases in the Least Active group (5.5\%). Again $1^{\text {st }}$ and $2^{\text {nd }}$ year males had decreases in the Most Active Group of $10 \%$ and $1 \%$ respectively along with $6^{\text {th }}$ year females who had a $9 \%$ decrease. Physical activity levels appear to have remained the same or increased through the middle section of post-primary school $\left(3^{\text {rd }}, 4^{\text {th }} \& 5^{\text {th }}\right.$ year $)$ as they decreased in both males and females at the beginning and end. Increases in the Least Active group are consistent with other investigations of physical activity levels in both Ireland (McGrath et al., 2020; O'Kane et al., 2021) and internationally (Lesser \& Nienhuis, 2020; Faulkner et al., 2021) as less active individuals were likely to become less active during Covid19 restrictions. One qualitative examination of physical activity during restrictions in Ireland found that adolescents reported a decline in motivation for exercise ( $O^{\prime}$ Kane et al., 2021) and that changed circumstances interrupted many automatic behaviour patterns through 'habit discontinuity' leading to formation of new habits or dropping previous habits and health behaviours (Wood \& Neal., 2016).

The largest decrease in terms of physical activity sub-group was observed in both males and females who participate in 3 or more sports as both decreased by $8 \%$. This is likely due to a reduction in access to activities as many community and school sports were cancelled due to restrictions. Males who remained involved in 3 or more sports had an increase in wellbeing and decrease in symptoms of anxiety while those who did not engage in any sport had a decrease in wellbeing and increase in symptoms of depression. Females who played 1, 2 and 3 or more sports had increases in symptoms of depression while those who played 3 or more had increases in symptoms of anxiety. Engagement in a number of sports appears to support higher levels of wellbeing and protect against symptoms of depression in males. This is consistent with previous cross-sectional examinations (McMahon et al., 2017; Murphy et al., 2020) and meta-analytic evidence (Panza et al., 2020) and has been attributed to increased opportunities for physical activity and social interaction that, independently, are protective factors (Eime, Young, Harvey, Charity \& Payne, 2013;).

Involvement in sport has also been linked to other health behaviours that influence mental disorders, such as diet, sleep and lifestyle choices, or may develop self-regulation skills for managing daily stressors (Fraser-Thomas, Cote \& Deakin, 2005, Paluska \& Schwenk, 2000). Engagement in team sport remained exactly the same in males although there was a $2 \%$ reduction for females. Males engaged in team sport had an increase in wellbeing and 
decrease in symptoms of anxiety. This aligns with previous research where it is suggested that team sport has a protective effect against symptoms of depression and anxiety (Murphy et al., 2020; McMahon et al., 2017; Panza et al., 2020) although this relationship may differ between genders as females engaged in team sport had decreases in wellbeing and increases in symptoms of depression. The difficulty of access to sporting opportunities may be a factor.

Our findings appear consistent with other research completed on physical activity during Covid-19 restrictions where overall levels of physical activity did not change, although many adolescents tried new forms of physical activity and patterns of activity changed (O'Kane et al., 2021). Available evidence suggests children and adolescents are less vulnerable to Covid19 than adults (Lee, Hu, Chen, Huang \& Hsueh, 2020) although some research suggests that adolescents have experienced higher rates of mental ill-health during restrictions (Riiser, Helseth, Haraldstad, Torbjornsen \& Richardsen, 2020). Covid-19 restrictions and social distancing can increase social isolation leading to adolescents feeling frustrated, nervous, disconnected and bored (Imran, Zeshan \& Pervaiz, 2020). Engagement in physical activity and sport provide adolescents with an opportunity to form social relationships which can increase motivation and enthusiasm (Davis \& Clifton, 1995). Loneliness has been highlighted as key contributor to decreased wellbeing during restrictions in other populations and is also associated with poorer perceived health, lower life satisfaction and lower ates of physical activity (McGrath et al., 2020).

Changes in physical activity levels appear to be somewhat polarised. An online survey investigating how restrictions impacted physical activity and wellbeing of Canadians found that inactive individuals were more likely to become less active while active individuals were more likely to increase activity levels (Lesser \& Nienhuis, 2020), most likely due to increased availability of time or motivation. Our findings highlight the importance of an awareness of activity levels as adolescents who were unsure of perceived changes in activity levels had the lowest wellbeing and highest symptoms of depression and anxiety. One specific component of wellbeing that has received increased attention recently is 'sense of purpose in life'. A bidirectional relationship has been found between sense of purpose and physical activity whereby an increased sense of purpose was associated with higher levels of physical activity while at the same time, increased physical activity was found to increase sense of purpose in life (Yemiscigil \& Vlaev, 2021). As both males and females who reported increasing or maintaining levels of physical activity during Covid-19 restrictions had the highest wellbeing it is very possible that previous levels of physical activity developed a sense of purpose in life and thereby led to higher wellbeing and physical activity during restrictions.

Limitations of this study include the use of a self-report questionnaires to measure frequency of physical activity, wellbeing, and symptoms of depression and anxiety which may be prone to recall bias and varying interpretations (Hallal et al., 2012) however, it is worth noting that constructs of wellbeing and perceived health status are subjective in their own right and the evaluation is pragmatic in its approach. The majority of schools who participated were of nonDEIS status meaning we lacked representation from schools of lower socio-economic status which may skew the results as it is not a true representative sample of the post-primary school population. Our study did not look at the specific details of what physical activity and sport opportunities were available on a school-by-school or sport-by-sport basis as there were large differences in what was offered to adolescents. This may also have impacted how active adolescents were and the context within which activity was conducted. 


\section{Conclusion}

This study adds to the knowledge base on the impact of restrictive measures implemented to reduce the transmission of Covid-19 on physical activity, wellbeing and symptoms of depression and anxiety in Irish adolescents. There were no changes in physical activity levels overall, although here were many changes within sub-groups and the patterns of physical activity. There was a clear increase in symptoms of depression, with females impacted more than males. Access to physical activity opportunities, especially sport, uncertainty about state examinations and decreased opportunities for social interaction are the most likely contributors to this increase in symptoms. Previously active individuals were more likely to increase activity and therefore report higher levels of mental health while those who were less active were more likely to decrease activity and report lower mental health.

\section{Acknowledgements}

The authors thank the survey participants, whose willingness to take the survey made this study possible. The authors are grateful to principals of participating schools for facilitating the completion of surveys during school time.

Funding source: Not applicable

\section{References}

Beck, A. T., Steer, R. A., \& Carbin, M. G. (1988). Psychometric properties of the Beck Depression Inventory: Twenty-five years of evaluation. Clinical psychology review, 8(1), 77-100.

Bekhuis, E., Schoevers, R. A., Van Borkulo, C. D., Rosmalen, J. G. M., \& Boschloo, L. (2016). The network structure of major depressive disorder, generalized anxiety disorder and somatic symptomatology. Psychological medicine, 46(14), 2989-2998.

Biddle, S. J., Ciaccioni, S., Thomas, G., \& Vergeer, I. (2019). Physical activity and mental health in children and adolescents: An updated review of reviews and an analysis of causality. Psychology of Sport and Exercise, 42, 146-155.

Biddle, S. J., Mutrie, N., Gorely, T., \& Faulkner, G. (2021). Psychology of physical activity: Determinants, well-being and interventions. Routledge.

Brown, A., Flint, S. W., Kalea, A. Z., O'Kane, M., Williams, S., \& Batterham, R. L. (2021). Negative impact of the first COVID-19 lockdown upon health-related behaviours and psychological wellbeing in people living with severe and complex obesity in the UK. EClinicalMedicine, 34, 100796.

Brown, M., O'Connor, D., Murphy, C., McClean, M., McMeekin, A., \& Prue, G. (2021). Impact of COVID-19 on an established physical activity and behaviour change support programme for cancer survivors: An exploratory survey of the Macmillan Move More service for Northern Ireland. Supportive Care in Cancer, 1-9.

Bull, F. C., Al-Ansari, S. S., Biddle, S., Borodulin, K., Buman, M. P., Cardon, G., ... \& Willumsen, J. F. (2020). World Health Organization 2020 guidelines on physical activity and sedentary behaviour. British journal of sports medicine, 54(24), 1451-1462.

Burkhardt, J., \& Brennan, C. (2012). The effects of recreational dance interventions on the health and well-being of children and young people: A systematic review. Arts \& Health, 4(2), 148-161. 
Clarke, A., Friede, T., Putz, R., Ashdown, J., Martin, S., Blake, A., ... \& Stewart-Brown, S. (2011). Warwick-Edinburgh Mental Well-being Scale (WEMWBS): validated for teenage school students in England and Scotland. A mixed methods assessment. BMC public health, 11(1), 1-9.

Costache, M. E., Frick, A., Månsson, K., Engman, J., Faria, V., Hjorth, O., ... \& Furmark, T. (2020). Higher-and lower-order personality traits and cluster subtypes in social anxiety disorder. PloS one, 15(4), e0232187.

Davis, D., \& Clifton, A. (1995). Psychosocial theory: Erikson Haverford University. Department of Psychology. Web site: http://www.haverford.edu/psych/ddavis/p109g/erikson. stages. html. Accessed July 5, 2021

Dooley, B., O'Connor, C., Fitzgerald, A., \& O'Reilly, A. (2019). My World Survey 2: The national study of youth mental health in Ireland http://www.myworldsurvey.ie/content/docs/My World Survey 2.pdf

Eime, R. M., Young, J. A., Harvey, J. T., Charity, M. J., \& Payne, W. R. (2013). A systematic review of the psychological and social benefits of participation in sport for children and adolescents: informing development of a conceptual model of health through sport. International journal of behavioral nutrition and physical activity, 10(1), 1-21.

Faulkner, J., O’Brien, W. J., McGrane, B., Wadsworth, D., Batten, J., Askew, C. D., ... \& Lambrick, D. (2021). Physical activity, mental health and well-being of adults during initial COVID-19 containment strategies: A multi-country cross-sectional analysis. Journal of science and medicine in sport, 24(4), 320-326.

Fraser-Thomas, J. L., Côté, J., \& Deakin, J. (2005). Youth sport programs: An avenue to foster positive youth development. Physical education \& sport pedagogy, 10(1), 19-40.

Fydrich, T., Dowdall, D., \& Chambless, D. L. (1992). Reliability and validity of the Beck Anxiety Inventory. Journal of anxiety disorders, 6(1), 55-61.

Hallal, P. C., Andersen, L. B., Bull, F. C., Guthold, R., Haskell, W., Ekelund, U., \& Lancet Physical Activity Series Working Group. (2012). Global physical activity levels: surveillance progress, pitfalls, and prospects. The lancet, 380(9838), 247-257.

Hyland, P., Shevlin, M., Elklit, A., Christoffersen, M., \& Murphy, J. (2016). Social, familial and psychological risk factors for mood and anxiety disorders in childhood and early adulthood: a birth cohort study using the Danish Registry System. Social psychiatry and psychiatric epidemiology, 51(3), 331-338.

Hyland, P., Shevlin, M., Murphy, J., McBride, O., Fox, R., Bondjers, K., ... \& Vallières, F. (2021). A longitudinal assessment of depression and anxiety in the Republic of Ireland before and during the COVID-19 pandemic. Psychiatry research, 300, 113905.

Imran, N., Zeshan, M., \& Pervaiz, Z. (2020). Mental health considerations for children \& adolescents in COVID-19 Pandemic. Pakistan journal of medical sciences, 36(COVID19S4), 567.

Kassebaum, N. J., Smith, A. G. C., Bernabé, E., Fleming, T. D., Reynolds, A. E., Vos, T., ... \& GBD 2015 Oral Health Collaborators. (2017). Global, regional, and national prevalence, incidence, and disability-adjusted life years for oral conditions for 195 countries, 1990-2015: a systematic analysis for the global burden of diseases, injuries, and risk factors. Journal of dental research, 96(4), 380-387.

Kendall, P. C., Hollon, S. D., Beck, A. T., Hammen, C. L., \& Ingram, R. E. (1987). Issues and recommendations regarding use of the Beck Depression Inventory. Cognitive therapy and research, 11(3), 289-299. 
Kieling, C., Baker-Henningham, H., Belfer, M., Conti, G., Ertem, I., Omigbodun, O., ... \& Rahman, A. (2011). Child and adolescent mental health worldwide: evidence for action. The Lancet, 378(9801), 1515-1525.

Kissler, S. M., Tedijanto, C., Goldstein, E., Grad, Y. H., \& Lipsitch, M. (2020). Projecting the transmission dynamics of SARS-CoV-2 through the postpandemic period. Science, 368(6493), 860-868.

Lee, P. I., Hu, Y. L., Chen, P. Y., Huang, Y. C., \& Hsueh, P. R. (2020). Are children less susceptible to COVID-19?. Journal of Microbiology, Immunology, and Infection, 53(3), 371.

Lesser, I. A., \& Nienhuis, C. P. (2020). The impact of COVID-19 on physical activity behavior and well-being of Canadians. International journal of environmental research and public health, 17(11), 3899.

Lin, K., Stubbs, B., Zou, W., Zheng, W., Lu, W., Gao, Y., ... \& Xu, G. (2020). Aerobic exercise impacts the anterior cingulate cortex in adolescents with subthreshold mood syndromes: a randomized controlled trial study. Translational Psychiatry, 10(1), 1-7.

McGrath, A., Murphy, N., \& Richardson, N. (2020). The impact of the COVID-19 pandemic on the wellbeing of Irish Men's Shed members. Health Promotion International.

McHugh Power, J., Hannigan, C., Hyland, P., Brennan, S., Kee, F., \& Lawlor, B. A. (2020). Depressive symptoms predict increased social and emotional loneliness in older adults. Aging \& mental health, 24(1), 110-118.

McMahon, E. M., Corcoran, P., O’Regan, G., Keeley, H., Cannon, M., Carli, V., ... \& Wasserman, D. (2017). Physical activity in European adolescents and associations with anxiety, depression and well-being. European child \& adolescent psychiatry, 26(1), 111-122.

Murphy, J., Sweeney, M. R., \& McGrane, B. (2020). Physical activity and sports participation in Irish adolescents and associations with anxiety, depression and mental wellbeing. Findings from the physical activity and wellbeing (paws) study. Physical Activity and Health, 4(1).

O’Kane, S. M., Lahart, I. M., Gallagher, A. M., Carlin, A., Faulkner, M., Jago, R., \& Murphy, M. H. (2021). Changes in Physical Activity, Sleep, Mental Health, and Social Media Use During COVID-19 Lockdown Among Adolescent Girls: A Mixed-Methods Study. Journal of Physical Activity and Health, 18(6), 677-685.

Paluska, S. A., \& Schwenk, T. L. (2000). Physical activity and mental health. Sports medicine, 29(3), 167-180.

Panza, M. J., Graupensperger, S., Agans, J. P., Doré, I., Vella, S. A., \& Evans, M. B. (2020). Adolescent sport participation and symptoms of anxiety and depression: A systematic review and meta-analysis. Journal of sport and exercise psychology, 42(3), 201-218.

Quispe, L. A. M., Panca, C. M. A., Ramos, A. P. T., \& Cornejo, J. M. (2021). Level of physical activity of Peruvian university students during confinement. Journal of Human Sport and Exercise, 16(2), 763-768.

Riiser, K., Helseth, S., Haraldstad, K., Torbjørnsen, A., \& Richardsen, K. R. (2020). Adolescents' health literacy, health protective measures, and health-related quality of life during the Covid-19 pandemic. PLoS One, 15(8), e0238161.

Sallis, J. F., Adlakha, D., Oyeyemi, A., \& Salvo, D. (2020). An international physical activity and public health research agenda to inform COVID-19 policies and practices. Journal of Sport and Health Science. 
Schuch, F. B., Vancampfort, D., Firth, J., Rosenbaum, S., Ward, P. B., Silva, E. S., ... \& Fleck, M. P. (2018). Physical activity and incident depression: a meta-analysis of prospective cohort studies. American Journal of Psychiatry, 175(7), 631-648.

Shapero, B. G., Farabaugh, A., Terechina, O., DeCross, S., Cheung, J. C., Fava, M., \& Holt, D. J. (2019). Understanding the effects of emotional reactivity on depression and suicidal thoughts and behaviors: Moderating effects of childhood adversity and resilience. Journal of affective disorders, 245, 419-427.

Smith, J., Griffith, D., White, A., Baker, P., Watkins, D., Drummond, M., \& Semlow, A. (2020). COVID-19, Equity and Men's Health. International Journal of Mens Social and Community Health, 3(1), e48-e64.

Steer, R. A., \& Beck, A. T. (1997). Beck Anxiety Inventory.

Steer, R. A., Kumar, G., Ranieri, W. F., \& Beck, A. T. (1995). Use of the Beck Anxiety Inventory with adolescent psychiatric outpatients. Psychological Reports, 76(2), 459-465.

Teri, L. (1982). The use of the Beck Depression Inventory with adolescents. Journal of abnormal child psychology, 10(2), 277-284.

Teychenne, M., White, R. L., Richards, J., Schuch, F. B., Rosenbaum, S., \& Bennie, J. A. (2020). Do we need physical activity guidelines for mental health: What does the evidence tell us?. Mental Health and Physical Activity, 18, 100315.

Wood, W., \& Neal, D. T. (2016). Healthy through habit: Interventions for initiating \& maintaining health behavior change. Behavioral Science \& Policy, 2(1), 71-83.

Woods, C., Powell, C., Saunders, J. A., O'Brien, W., Murphy, M. H., Duff, C., ... \& Belton, S. (2019). The children's sport participation and physical activity study 2018 (CSPPA 2018).

Woods, J., Hutchinson, N. T., Powers, S. K., Roberts, W. O., Gomez-Cabrera, M. C., Radak, Z., ... \& Ji, L. L. (2020). The COVID-19 pandemic and physical activity.

Yemiscigil, A., \& Vlaev, I. (2021). The bidirectional relationship between sense of purpose in life and physical activity: a longitudinal study. Journal of Behavioral Medicine, 1-11.

Zhai, L., Zhang, Y., \& Zhang, D. (2015). Sedentary behaviour and the risk of depression: a meta-analysis. British journal of sports medicine, 49(11), 705-709.

Zhou, J., Heim, D., \& O'Brien, K. (2015). Alcohol consumption, athlete identity, and happiness among student sportspeople as a function of sport-type. Alcohol and alcoholism, 50(5), 617-623. 